\title{
Models for Predicting Thermal Performance of Packed Bed Energy Storage System for Solar Air Heaters - A Review
}

\author{
Ranjit Singh $^{*}, 1$, R.P. Saini ${ }^{2}$ and J.S. Saini ${ }^{3}$ \\ ${ }^{1}$ Department of Mechanical Engineering, Beant College of Engineering and Technology, Gurdaspur, Punjab, 143521, \\ India \\ ${ }^{2}$ Alternate Hydro Energy Centre, ${ }^{3}$ Mechanical and Industrial Engineering Department, Indian Institute of Technology, \\ Roorkee, Uttarakhand, 247667, India
}

\begin{abstract}
Packed bed is generally recommended for attaching with solar air heater in order to store thermal energy of hot air. For designing such a system under the given system and operating parameters, it is required to predict performance of the system by using mathematical models. In the present paper an attempt has been made to discuss mathematical models reported in the literature for predicting thermal performance of packed bed energy storage system for solar air heaters. The designer may be benefited from the consolidated information reported in the present paper.
\end{abstract}

Keywords: Packed bed, solar energy, solar air heater.

\section{INTRODUCTION}

The continuous use of fossil fuels resulted energy crisis and environmental threat. It is felt that renewable energy sources are quite capable of meeting energy demand of today's world. The use of renewable energy sources for meeting energy needs can conserve the conventional energy sources for more number of decades. Among renewable energy sources solar energy is considered to be one of the most dominating energy source. It has many advantages like large potential, free of cost, available everywhere, environment friendly etc. However time dependent nature is the major disadvantage of solar energy. In order to overcome this disadvantage it is required to attach an energy storage system with the solar energy utilization system. With such a provision the stored energy can be utilized in the absence of solar radiation or under peak load conditions.

In case of solar air heaters it is required to store thermal energy of flowing hot air. Packed bed is generally recommended for such an application. Packed bed consists of a container in which solid material elements having good heat capacity remain packed. The hot air flows from top to bottom of the bed to transfer heat energy. The rise in temperature of solid material takes place and energy can be retained by having properly insulated packed bed. The stored energy can be retrieved by making flow of cold air from bottom to top of the bed. The schematic of packed bed energy storage system for solar air heaters is shown in Fig. (1). The working of such a system is described in detail by Duffie and Beckman [1].

In order to design packed bed energy storage system for the given system and operating parameters, it is required to

*Address correspondence to this author at the Department of Mechanical Engineering, Beant College of Engineering and Technology, Gurdaspur, Punjab, 143521, India; Tel: +91 1874 221464;

E-mail: rsolar70@yahoo.co.in predict performance of such type of a system. In the present paper an attempt has been made to discuss mathematical models reported in the literature for predicting thermal performance of packed bed energy storage system for solar air heaters. The designer can be benefited from the consolidated information reported in the present paper.

\section{THERMAL PERFORMANCE OF PACKED BED}

Thermal performance of a packed bed is concerned with heat transfer from flowing air to solid material packed in a container and vice versa. Hot air flows from top to bottom of the bed and heat transfer takes place from air to storage material during charging phase. The rate of heat transfer to or from the storage material elements in a packed bed is a function of physical properties of air and solid, local temperature of air and surface of material elements, mass flow rate of air and characteristics of the packed bed. The bed may be arranged in an orderly or randomly fashion. Random packing is the most common arrangement and results when particles of the same approximate size and shape are packed in a container. The characteristics of the packed bed are dependent upon the shape and orientation of the storage material elements and void fraction of the bed. Heat transfers between air and solid through a complex mechanism. Major resistance to heat transfer takes place at the interface of air and solid and is inversely proportional to the convective heat transfer coefficient. Rise in temperature of material elements is dependent upon transient heat conduction from surface to interior of the solid. It also depends, to a lesser degree, on inter-particle conduction of heat when the adjacent material element comes in direct physical contact. Transfer of heat through the container walls also influences performance of the packed bed. Another factor influencing the rate of heat transfer is mixing action within the air that results from the eddies created as the fluid flows through the complex set of flow passages. 


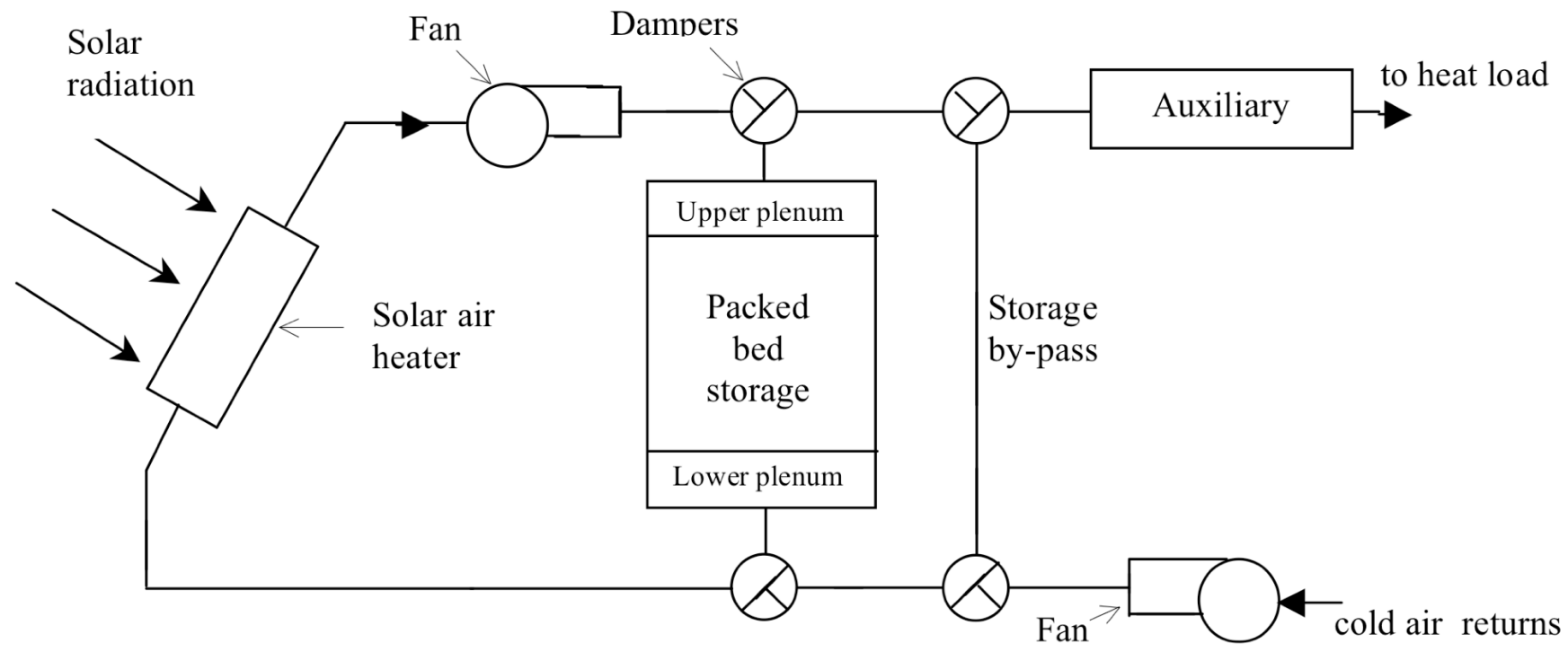

Fig. (1). Schematic of packed bed energy storage system for solar air heaters.

\section{MODELS FOR PREDICTING THERMAL PERFORMANCE OF PACKED BED}

In order to predict thermal performance of a packed bed system, several models have been reported in literature based on the theoretical and experimental investigations. A typical packed bed unit of length or height ' $L$ ', diameter ' $D_{b}$ ' and cross sectional area ' $\mathrm{A}$ ' packed with material elements and having void fraction ' $\varepsilon$ ' as shown in Fig. (2) is considered to report and discuss these mathematical models in the following sections. It is assumed that initial uniform temperature of the bed is ' $\mathrm{T}_{\mathrm{bi}}$ '. The air enters at mass flow rate ' $\dot{m}$ ' and temperature ' $\mathrm{T}_{\mathrm{ai}}$ '. The temperature of air at exit of the bed is ' $\mathrm{T}_{\mathrm{ao}}$ '. The bed is assumed to consist of ' $\mathrm{N}$ ' number of elements of thickness $\Delta x$ each. One of the bed element ' $m$ ' at initial uniform temperature $T_{b, m}$ is shown in Fig. (3). Air enters into this bed element at temperature $\mathrm{T}_{\mathrm{a}} \mathrm{m}$ and exits at $\mathrm{T}_{\mathrm{a}, \mathrm{m}+1}$ as has been described by Howell et al. [2].

\subsection{Two Phase Model (Schumann Model)}

A packed bed in solar heating system does not normally operate with constant inlet temperature. During the day, variable solar radiation, ambient temperature, collector inlet temperature, load requirements and other time dependent conditions result in variable collector outlet temperature. This leads to transient inlet condition of the packed bed during charging. For determination of transient response of packed bed heat storage units, two phase and single-phase models have been proposed. Two-phase models allow fluid and solid temperatures to be different, with an inter phase heat transfer described by a mean heat transfer coefficient. It is reported in literature that the first analytical study on modeling of a packed bed was conducted by Schumann and most of the work reported till date has been focused on Schumann model. This model predicts mean fluid and solid temperatures at a given cross-section as a function of axial

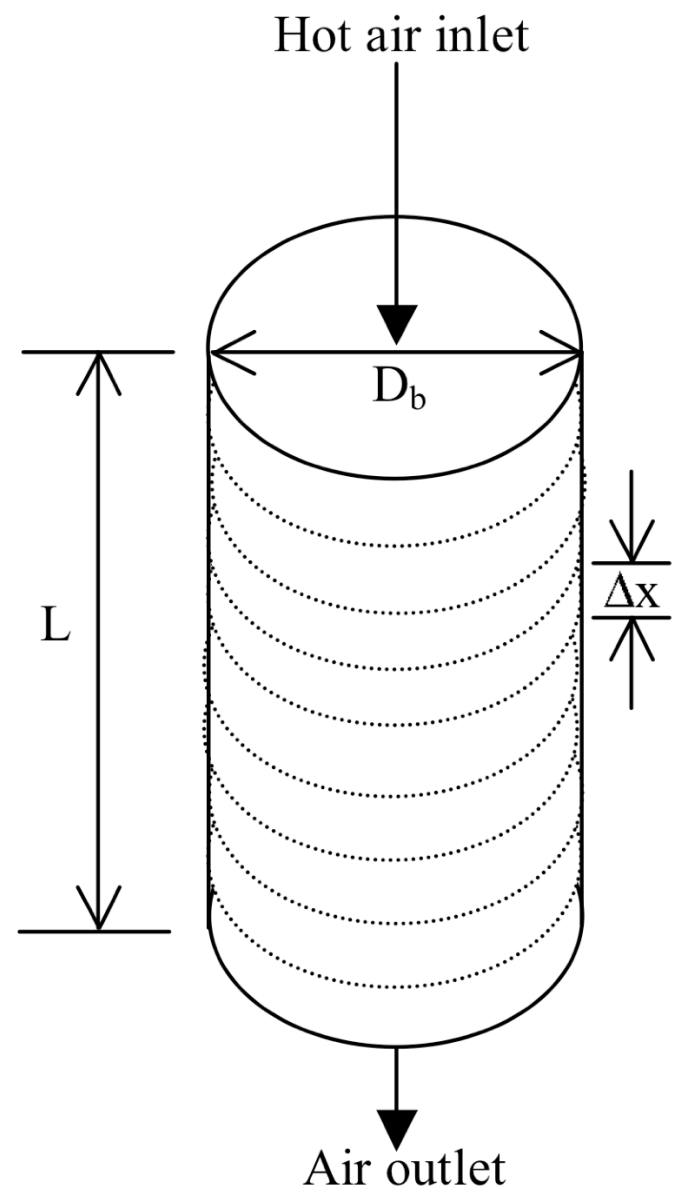

Fig. (2). Packed bed (voids are not shown).

position and time. Duffie and Beckman [1] presented Schumann's two-phase model of packed bed system as has been discussed below. 


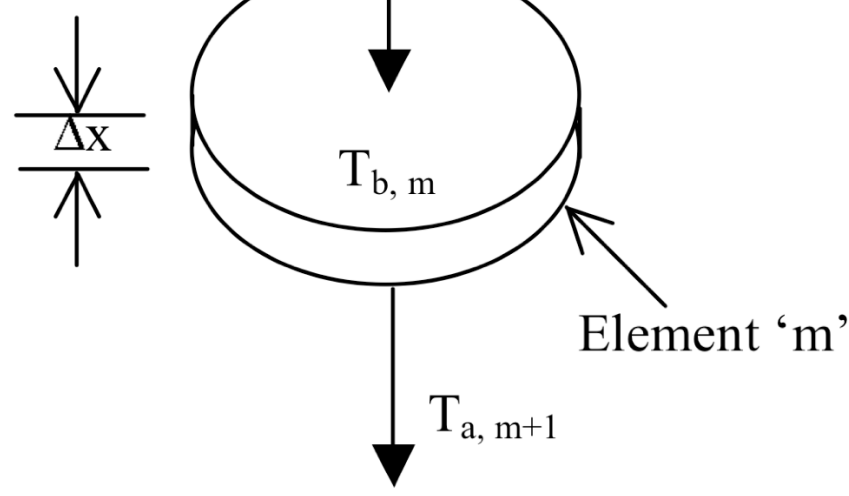

Fig. (3). Element ' $m$ ' of packed bed.

Assumptions made in Schumann's two-phase model are;

(i). Bed material has an infinite thermal conductivity in the radial direction and the flow is plug flow i.e. no temperature gradients in the radial direction.

(ii). Bed material has zero thermal conductivity in axial direction.

(iii). Thermal and physical properties of both solid and fluid are uniform and constant.

(iv). Heat transfer coefficient does not vary with time and place inside the bed.

(v). No fluid phase axial conduction or dispersion takes place.

(vi). No mass transfer occurs.

(vii). No heat loss to environment.

(viii). No thermal capacitance of the fluid.

Energy balance for air is given as;

Rate of energy supply by air at entry to the bed $=$ (Rate of energy transfer to bed material) + (Rate of energy accumulation by air in the bed) + (Rate of energy leaving the bed with flowing air) + (Rate of energy loss to environment)

It can be represented mathematically as;

$\left(\dot{m} C_{p}\right)_{a} T_{a i}=h_{v}\left(T_{a}-T_{b}\right) A d x+$

$+\left(\rho C_{p}\right)_{a} \varepsilon A d x \frac{\partial T_{a}}{\partial t}+\left(\dot{m} C_{p}\right)_{a}\left(T_{a i}+\frac{\partial T_{a i}}{\partial x} d x\right)$

$+U l_{p} d x\left(T_{a}-T_{a m b}\right)$

Energy accumulated with air in the bed and energy loss to the environment can be neglected as per the assumptions. By multiplying with ' $L$ ' on both sides, the above equation can be written as;

$$
\frac{\partial T_{a i}}{\partial(x / L)}=-\frac{h_{v} A L}{\left(\dot{m} C_{p}\right)_{a}}\left(T_{a}-T_{b}\right)
$$

or $\frac{\partial T_{a i}}{\partial(x / L)}=-N T U\left(T_{a}-T_{b}\right)$

or $\frac{\partial T_{a}}{\partial(x / L)}=-N T U\left(T_{a}-T_{b}\right)$

where $N T U$ (Number of Transfer Units) $=\frac{h_{v} A L}{\left(\dot{m} C_{p}\right)_{a}}$

Energy balance for material elements can be written as;

Rate of energy transfer by air to the material elements = Rate of energy storage in the material elements

$h_{v}\left(T_{a}-T_{b}\right) A \cdot d x=\left(\rho C_{p}\right)_{s}(1-\varepsilon) A d x \frac{\partial T_{b}}{\partial t}$

Multiplying by ' $L$ ' and dividing by $\left(\dot{m} C_{p}\right)_{a}$ on both sides of above equation;

$\frac{\left(\rho C_{p}\right)_{s}}{\left(\dot{m} C_{p}\right)_{a}}(1-\varepsilon) A L \frac{\partial T_{b}}{\partial t}=\frac{h_{v} A L}{\left(\dot{m} C_{p}\right)_{a}}\left(T_{a}-T_{b}\right)$

or $\frac{\partial T_{b}}{\partial \tau}=N T U\left(T_{a}-T_{b}\right)$

where $\tau$ (dimensionless time) $=\frac{\left(\dot{m} C_{p}\right)_{a} t}{\left(\rho C_{p}\right)_{s}(1-\varepsilon) A L}$

Eqs. (4) and (8) are partial differential equations which describe thermal performance of a packed bed. Air temperature leaving the bed element ' $\mathrm{m}$ ' may be obtained by integrating Eq. (4) as given below;

$\int_{m}^{m+1} \frac{\partial T_{a}}{T_{a}-T_{b}}=-\int N T U \partial(x / L)$

or $\ln \frac{T_{a, m+1}-T_{b, m}}{T_{a, m}-T_{b, m}}=-N T U(\Delta x / L)$

or $\frac{T_{a, m+1}-T_{b, m}}{T_{a, m}-T_{b, m}}=e^{-N T U / N}$

where $N=L / \Delta x$

Eq. (12) can be written as;

$\frac{T_{a, m}-T_{a, m+1}}{T_{a, m}-T_{b, m}}=1-e^{-N T U / N}$

Rate of energy transfer from air to bed element of thickness ' $\Delta x$ ' is given by;

$q=\left(\dot{m} C_{p}\right)_{a}\left(T_{a, m}-T_{a, m+1}\right)$ 
Substituting value of $\left(T_{a, m}-T_{a, m+1}\right)$ from Eq. (14) in above equation;

$\left(\dot{m} C_{p}\right)_{a}\left(T_{a, m}-T_{a, m+1}\right)$

$=\left(\dot{m} C_{p}\right)_{a}\left(T_{a, m}-T_{b, m}\right)\left(1-e^{-N T U / N}\right)$

Air temperature at exit of bed elements can be obtained by solving above equation.

Similarly Eq. (8) can be transformed to obtain mean temperature of bed element ' $\mathrm{m}$ ' as given below;

$$
\frac{d T_{b, m}}{d \tau}=C N\left(T_{a, m}-T_{b, m}\right)
$$

where $C$ is a constant and equal to $1-e^{-N T U / N}$. An extension to Eq. (17) permits energy loss to environment at temperature $T_{a m b}$. Therefore, above equation can be written as;

$$
\frac{d T_{b, m}}{d \tau}=C N\left(T_{a, m}-T_{b, m}\right)+\frac{(U \Delta A)_{m}}{\left(\dot{m} C_{p}\right)_{a}}\left(T_{a m b}-T_{b, m}\right)
$$

Eq. (18) can be solved by finite difference method. Initially all bed elements are at ' $\mathrm{T}_{\mathrm{bi}}$ ' (initial bed temperature). The process will start at bed element ' 1 ' to which an inlet air temperature is known. An outlet air temperature from Eq. (16) and a new mean temperature of bed element can be calculated from Eq. (18). This outlet air temperature will become an inlet temperature for bed element ' 2 '. This process will continue till last element of the bed.

\subsection{Intraparticle Conduction and Dispersion Model}

As described above, Schumann model is based on number of assumptions. Hughes et al. [3] discussed these assumptions in detail. Sodha et al. [4] mentioned that assumption of infinite thermal conductivity is not realistic, since most materials used for thermal storage are poor conductors of heat. The assumptions of Schumann model like temperature gradients within the particles of the packed bed are not significant and there is no axial conduction and dispersion in the packed bed are relaxed by presenting an approach suggested by Jaffreson [5] for corrected value of $N T U$ i.e. $N T U_{c}$.

$$
\frac{1}{N T U_{c}}=\frac{D_{e}}{L(P e)}+\frac{1+B i / 5}{N T U}
$$

where ' $B i$ ' and ' $P e$ ' are Biot and Paclet number respectively. Biot number accounts for temperature gradients in material elements and Paclet number accounts for axial conduction and dispersion in the bed. NTU can be estimated using the correlation for volumetric heat transfer coefficient reported by Löf \& Hawley [6]. If Biot number is less than 0.1 , temperature gradients within the material elements can be neglected. By comparing predictions of packed bed behavior with experimental results, Jeffreson [5] reported that the modified $N T U$ adequately accounts for these additional effects. $N T U_{c}$ can be used instead of $N T U$ in any of the equations presented in previous sections to include effects of temperature gradients in the material elements and axial conduction and dispersion in the bed. Many investigations have been reported in literature concerning conduction and dispersion in packed beds [7]-[19].

Therefore, Eqs. (4) and (8) respectively can be transformed as given below;

$$
\frac{\partial T_{a}}{\partial(x / L)}=-N T U_{c}\left(T_{a}-T_{b}\right)+\frac{(U \Delta A)_{m}}{\left(\dot{m} C_{p}\right)_{a}}\left(T_{a m b}-T_{a}\right)
$$

$\frac{\partial T_{b}}{\partial \tau}=N T U_{c}\left(T_{a}-T_{b}\right)$

Eq. (20) has been obtained by including energy loss term in Eq. (4) in addition to replacement of $N T U$ by $N T U_{c}$. Eqs. (20) and (21) can be solved by finite difference method. This model can be used to estimate the long-term thermal performance of packed bed solar energy storage system.

\subsection{Single Phase Model}

The repetitive solution of Schumann model, even in the form of Eq. (18) is considered to be time consuming for year long solar process calculations. This observation led Hughes et al. [3] to investigate an infinite $N T U_{c}$ model.

For infinite $N T U_{c}$, Eqs. (4) and (8) can be combined into a single partial differential equation since solid and fluid temperatures in the bed are equal. Instead of two coupled partial differential equations as required by the Schumann model, the packed bed model for infinite $N T U_{c}$ has a single partial differential equation. As $N T U_{c}$ becomes infinitely large, solid and air temperature at any point in the bed become identical. It is reported that long-term performance of a solar air heating system with $N T U_{c}$ equal to 25 is virtually the same as that with $N T U_{c}$ equal to infinity. By including energy loss term, governing equation for this model can be written as;

$$
\frac{\partial T}{\partial \tau}=-L \frac{\partial T}{\partial x}+\frac{(U \Delta A)_{m}}{\left(\dot{m} C_{p}\right)_{a}}\left(T_{a m b}-T_{a}\right)
$$

where ' $\mathrm{T}$ ' is an identical temperature for both air and solid temperature in the bed.

The above equation can be solved approximately by using finite difference method. The accuracy of this finite difference method depends upon the choice of ' $N$ ' i.e. the number of isothermal segments in the bed. As ' $N$ ' increases, accuracy of the solution method improves, but at the expense of additional calculation effort. Hughes et al. [3] reported that in order to determine a practical value of ' $\mathrm{N}$ ' the results of simulations of many system designs for various values of ' $N$ ' have been compared with the results obtained using the Sachumann model with $N T U_{c}$ of 25 . It has been found that the infinite $N T U_{c}$ model having ' $N$ ' value of 5 presents a reasonable compromise between accuracy and calculation effort.

\subsection{Equivalence of Two Phase and Single Phase Models}

Two phase and single-phase models are equivalent to each other for transient response of packed bed having 
$N T U_{c} \geq 10$. Single-phase model is simpler than two phase Sachumann model. Vortmeyer and Schaefer [20] demonstrated the equivalence of single phase and two-phase models. Riaz [21] mentioned that the close agreement between the transient responses of single and two phase models of a packed bed suggests that they are equivalent and therefore, can be effectively combined.

\subsection{Cautier and Farber Model}

As discussed above that Sachumann model works under number of assumptions. Therefore, Cautier and Farber [22] stated that Schumann model can not be applied, when dealing with solar applications, because actual conditions are too restrictive for Schumann's mathematical treatment. Authors presented a two-phase model, which includes effect of thermal losses, air capacitance and conduction between material elements. Two-phase model is presented as;

$$
\begin{aligned}
& \frac{\partial T_{a}}{\partial Y}+K_{3} \frac{\partial T_{a}}{\partial Z}=T_{b}-T_{a}-K_{1}\left(T_{a}-T_{a m b}\right) \\
& \frac{\partial T_{b}}{\partial Z}=T_{a}-T_{b}+K_{2} \frac{\partial^{2} T_{b}}{\partial Y^{2}}
\end{aligned}
$$

where $Y=\alpha x=\frac{h_{v}}{\left(G C_{p}\right)_{a}} x$

and $Z=\beta t=\frac{h_{v}}{\left(\rho C_{p}\right)_{s}(1-\varepsilon)} t$

Dimensionless coefficients $K_{1}, K_{2}, K_{3}$ respectively correspond to the terms accounting for heat loss to surroundings, conduction effect and air capacitance. These can be neglected due to their small values for normal conditions encountered in solar applications. This is why many authors neglected them and worked on the simple set of equations.

\subsection{Sagara and Nakahara Model}

Power spent to propel air through the bed reduces overall benefit of solar energy utilization system. Energy consumption by fan depends upon pressure drop in the bed. Packing of small size elements of storage material causes large pressure drop in the bed. Sagara and Nakahara [23] reported that packing of large size elements of storage material could reduce pressure drop in the bed. Since temperature gradients exist in large size material elements, uniform temperature distribution in large size elements of storage material can not be assumed. Sagara and Nakahara modified Schumann model to take into account the effect of temperature gradients on thermal performance of the bed. It is assumed that temperature within the material elements is distributed quadratically and symmetrically about their center. Following are two phase model equations for air and solid presented by Sagara and Nakahara [23];

$$
K \frac{\partial T_{a}^{*}}{\partial t^{*}}+\frac{\partial T_{a}^{*}}{\partial x^{*}}=L^{*}\left(T_{b, m}^{*}-M T_{a}^{*}\right)
$$

where $K=\frac{\left(\rho C_{p}\right)_{a} \varepsilon}{\left(\rho C_{p}\right)_{s}(1-\varepsilon)}$

and $M=1+\frac{U l_{p}}{h_{v} A}$

$\frac{\partial T_{b, m}^{*}}{\partial t^{*}}=L^{*}\left(T_{a}^{*}-T_{b m}^{*}\right)$

$T_{a}^{*}, T_{b}^{*}, x^{*}$ and $t^{*}$ are non-dimensional variables for $T_{a}$, $T_{b}, x$ and $t$ respectively as expressed below;

$$
\begin{aligned}
T_{a}^{*} & =\frac{T_{a}-T_{b i}}{T_{a i}-T_{b i}} \\
T_{b}^{*} & =\frac{T_{b}-T_{b i}}{T_{a i}-T_{b i}} \\
x^{*} & =\frac{x}{l_{x}} \\
t^{*} & =\frac{\left(\dot{m} C_{p}\right)_{a} t}{\left(\rho C_{p}\right)_{s}(1-\varepsilon) V}
\end{aligned}
$$

$L^{*}$ expressed in Eq. (30) is identical to modified NTU or $\mathrm{NTU}_{\mathrm{c}}$.

$$
L^{*}=N T U_{c}=\frac{3 L}{B+3}
$$

where $L=N T U=\frac{h_{v} V}{\left(\dot{m} C_{p}\right)_{a}}$

and $B=\frac{h_{v} R^{2}}{3 k_{s}(1-\varepsilon)}$

Eqs. (27) and (30) are same as Schumann model, except that $L$ (NTU) is replaced with $L^{*}\left(\mathrm{NTU}_{\mathrm{c}}\right)$, which is introduced to account for finite thermal conductivity of the solid. If thermal conductivity of solid material is infinite $\left(k_{s} \rightarrow \infty\right)$, Eqs. (27) and (30) become completely identical to Schumann model. Sagara and Nakahara presented heat transfer coefficient correlations for different shapes of material elements at different void fractions in order to solve Eqs. (27) and (30). Based on an extensive experimental investigation, Singh et al. [24] presented the following correlation for Nusselt number to calculate heat transfer coefficient for a bed at different void fractions and packed with large size material elements of different shapes. 


$$
N u=0.437(\mathrm{Re})^{0.75}(\psi)^{3.35}(\varepsilon)^{-1.62}\left[\exp \left\{29.03(\log \psi)^{2}\right\}\right]
$$

\subsection{Mumma and Marvin Model}

Mumma and Marvin proposed a straightforward simulation method for the thermal behavior of a packed bed storage systems as has been reported by Howell et al. [2]. The simulation is based on one-dimensional transient analysis of energy exchange between air stream and material elements, using a finite difference method. Energy balance of air over length $\Delta \mathrm{x}(=\mathrm{L} / \mathrm{N})$ of bed element 'm' (shown in Fig. 3) is given by;

$$
\begin{aligned}
& \left(\dot{m} C_{p}\right)_{a} d T_{a}=\left(\dot{m} C_{p}\right)_{a}\left(T_{a, m}-T_{a, m+1}\right) \\
& =h_{v} A \Delta x\left(T_{a, m}-T_{b, m}\right)
\end{aligned}
$$

The above equation can be integrated to find temperature of air ' $T_{a, m+1}$ ' at exit of each element.

$\int_{0}^{\Delta x} \frac{d T_{a}}{\left(T_{a, m}-T_{b, m}\right)}=\int_{0}^{\Delta x} \frac{h_{v} A d x}{\left(\dot{m} C_{p}\right)_{a}}=\frac{h_{v} A L}{N\left(\dot{m} C_{p}\right)_{a}}=\frac{N T U}{N}=\phi_{1}$

where $N T U$ (Number of Transfer Units) $=\frac{h_{v} A L}{\left(\dot{m} C_{p}\right)_{a}}$

or $T_{a, m+1}=T_{b, m}+\left(T_{a, m}-T_{b, m}\right) \exp \left(-\phi_{1}\right)$

An energy balance on the storage material in element ' $\mathrm{m}$ ' for time increment ' $\mathrm{dt}$ ' can be written as;

Rate of change in internal energy of storage material = (Rate of energy gain from air) - (Rate of energy loss to surroundings)

It can be represented mathematically as;

$$
\begin{aligned}
& \left(\rho C_{p}\right)_{s}(1-\varepsilon) A \Delta x \frac{d T_{b, m}}{d t}=\left(\dot{m} C_{p}\right)_{a}\left(T_{a, m}-T_{a, m+1}\right)- \\
& -(U \Delta A)_{m}\left(T_{b, m}-T_{a m b}\right)
\end{aligned}
$$

Eq. (41) can be written in finite difference form as;

$T_{b, m(t+\Delta t)}=T_{b, m(t)}+\left[\phi_{2}\left(T_{a, m}-T_{a, m+1}\right)-\phi_{3}\left(T_{b, m}-T_{a m b}\right)\right] \Delta t$

where $\phi_{2}=\frac{\left(\dot{m} C_{p}\right)_{a} N}{\left(\rho C_{p}\right)_{s} A L(1-\varepsilon)}, \phi_{3}=\frac{(U \Delta A)_{m}}{\left(m C_{p}\right)_{a}} \phi_{2}$

and $\Delta t$ is time increment.

Eqs. (42) and (44) can be used to calculate the system behavior once $\phi_{1}, \phi_{2}$, and $\phi_{3}$ are specified along with initial conditions of bed temperature. It is mentioned by the authors that the above numerical analysis provides stable predictions of bed temperatures that compare well with analytical solutions if time increment and bed element size are related as:

$\Delta \mathrm{t} \leq\left\{\phi_{2}\left[1-\exp \left(-\phi_{1}\right)\right]\right\}^{-1}$

\section{CONCLUSION}

In order to design packed bed energy storage system for the given system and operating parameters, it is required to predict performance of such type of a system. In the present paper an attempt has been made to review the mathematical models reported in the literature for predicting thermal performance of packed bed energy storage system for solar air heaters. The designer can be benefited from the consolidated information reported in the present paper.

\section{NOMENCLATURE}

$A$

$\Delta A$

$B i$

$C_{p}$

$D_{e}$

$G$

$h_{v}$

$k_{s}$

$L, l_{x}$

$l_{p}$

$\dot{m}$

N

$\mathrm{Nu}$

NTU

$N T U_{c}$

$P e$

$R$

$\operatorname{Re}$

$T_{a}$

$T_{a i}$

$T_{a, m}$

$T_{a, m+1}$

$T_{a m b}$

$T_{b}$
$=$ Cross sectional area of packed bed, $\mathrm{m}^{2}$

$=$ External surface area of bed element ' $\mathrm{m}$ ', $\mathrm{m}^{2}$

$=$ Biot number, dimensionless

$=$ Specific heat, $\mathrm{J} \mathrm{kg}^{-1} \mathrm{~K}^{-1}$

$=$ Equivalent diameter of material particle, $\mathrm{m}$

$=$ Mass velocity of air, $\mathrm{kg} \mathrm{s}^{-1} \mathrm{~m}^{-2}$

$=$ Volumetric heat transfer coefficient, $\mathrm{Wm}^{-3} \mathrm{~K}^{-1}$

$=$ Thermal conductivity of solid material, $\mathrm{Wm}^{-1} \mathrm{~K}^{-1}$

$=$ Length or height of the bed, $\mathrm{m}$

$=$ Perimeter, $\mathrm{m}$

$=$ Mass flow rate, $\mathrm{kg} \mathrm{s}^{-1}$

$=$ Number of bed elements, dimensionless

$=$ Nusselt number, dimensionless

$=$ Number of Transfer Units, dimensionless

$=$ Corrected or modified Number of Transfer Units, dimensionless

$=$ Paclet number, dimensionless

$=$ Distance from surface to center of material element, $\mathrm{m}$

$=$ Reynolds number, dimensionless

$=$ Average temperature of air in the bed, ${ }^{\circ} \mathrm{C}(\mathrm{K})$

$=$ Temperature of air at inlet to the bed, ${ }^{\circ} \mathrm{C}(\mathrm{K})$

$=$ Temperature of air at inlet to the bed element 'm', ${ }^{\circ} \mathrm{C}(\mathrm{K})$

$=$ Temperature of air at outlet of bed element 'm', ${ }^{\circ} \mathrm{C}(\mathrm{K})$

$=$ Ambient temperature, ${ }^{\circ} \mathrm{C}(\mathrm{K})$

$=$ Mean temperature of bed, ${ }^{\circ} \mathrm{C}(\mathrm{K})$ 


$$
\begin{array}{lll}
T_{b i} & = & \text { Initial temperature of bed, }{ }^{\circ} \mathrm{C}(\mathrm{K}) \\
T_{b, m} & = & \text { Mean temperature of bed element ' } \mathrm{m} \text { ', }{ }^{\circ} \mathrm{C} \\
& & (\mathrm{K}) \\
t & = & \text { Time, } \mathrm{s} \\
\Delta t & = & \text { Time interval/increment, } \mathrm{s}(\mathrm{min}) \\
U & = & \text { Overall heat loss coefficient, } \mathrm{Wm}^{-2}{ }^{2} \mathrm{C}^{-1} \\
& & \left(\mathrm{Wm}^{-2} \mathrm{~K}^{-1}\right) \\
V & = & \text { Volume of packed bed, } \mathrm{m}^{3} \\
x & = & \text { Distance along the bed, } \mathrm{m} \\
\Delta x & = & \text { Height or thickness of bed element ' } \mathrm{m} \text { ', } \mathrm{m} \\
\rho & = & \text { Density, } \mathrm{kg} \mathrm{m}^{-3} \\
\varepsilon & = & \text { Void fraction, dimensionless } \\
\psi & = & \text { Sphericity, dimensionless } \\
\text { Suffix } & \\
\mathrm{a} & = & \text { Air } \\
\mathrm{s} & = & \text { Solid }
\end{array}
$$

[19] Gunn, D. J. Axial and radial dispersion in radial beds. Chem. Eng. Sci., 1987, 42, 363-373.

[20] Vortmeyer, D.; Schaefer, R. J. Equivalence of one and two phase models for heat transfer in packed beds: one dimensional theory. Chem. Eng. Sci., 1974, 29, 485-491.

[21] Riaz, M. Analytical solutions for single and two phase models of packed bed thermal storage systems. J. Heat Transf. (ASME Trans.), 1977, 99, 489-492.

[22] Cautier, J. P.; Farber, E. A. Two applications of a numerical approach of heat transfer process within rock beds. Solar Energy, 1982, 29, 451-462.

[23] Sagara, K.; Nakahara, N. Thermal performance and pressure drop of packed beds with large storage materials. Solar Energy, 1991, 47, 157-163.

[24] Singh, R.; Saini, R. P.; Saini, J.S. Nusselt number and friction factor correlations for packed bed solar energy storage system having large sized elements of different shapes. Solar Energy, 2006, 80, 760-771.

\footnotetext{
AIChE J., 1972, 18, 409-416.

[6] Löf, G. O. G.; Hawley, R. W. Unsteady state heat transfer between
}

[5] Jeffreson, C. P. Prediction of break through curves in packed beds. air and loose solids. Ind. Eng. Chem., 1948, 40, 1061-1070. 